\title{
Atores políticos, informação e democracia
}

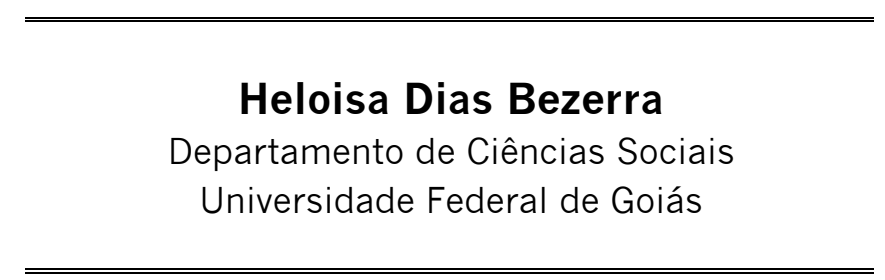

Resumo: A produção e difusão de informações políticas devem ser incluídas nas prioridades dos atores políticos? Quais as vantagens para a democracia trazidas pela participação ativa das instituições no mercado informacional? Este artigo apresenta algumas questões relativas à importância do incremento do fluxo de informações proveniente dos atores políticos para a sociedade civil.

Palavras-chave: informação política; accountability; persuasão; esfera pública; participação.

\begin{abstract}
The production and diffusion of political information must be included like priorities by political actors? Which are the advantages to democracy by active participation of the political institutions in the informational market? This paper presents some questions concerning the importance of the increase the flow of information from political actors to civil society.
\end{abstract}

Keywords: political information; accountability; persuasion; public sphere; participation. 
BEZERRA, H. D. Atores políticos, informação e democracia.

\section{Introdução ${ }^{1}$}

O impacto das novas tecnologias de informação e comunicação (TIC) nas relações entre Estado e sociedade tem sido objeto de inquietação por parte de especialistas das mais diferentes áreas do conhecimento. Grosso modo, pode-se afirmar que há uma clara divisão em termos de pontos de vista quanto aos reais benefícios das TICs no que tange às possibilidades de interação propositiva dos cidadãos nas decisões dos poderes públicos. Basicamente temos um grupo propenso ao otimismo e outro mais inclinado ao pessimismo quanto à expansão da participação decorrente dos avanços tecnológicos (NORRIS, 2002; SANCHEZ, 2003; BRAGA, 2004, 2006; SILVA, 2005; MARQUES, 2006).

Para fins didáticos, fiz uma releitura de dois modelos utilizados pela literatura especializada ${ }^{2}$ e, acrescentando aos mesmos elementos da teoria política clássica e contemporânea, os denominei por "cyberotimistas rousseanianos" e "cyberpessimistas schumpeterianos"3. Os primeiros estão relacionados à percepção de que as novas TICs constituem um surpreendente caminho para novos padrões de interação em ambientes democráticos, avanços que supostamente poderiam ser observados tanto na postura de políticos e burocratas, quanto nos próprios cidadãos, fazendo coro, assim, aos ideais do deliberacionismo ou do participativismo. Por seu turno, os "cyberpessimistas schumpeterianos" não acreditam nessa possibilidade incremental das TICs no que tange à participação política, seja pela inexistência de interesse por parte daqueles que estão à frente dos poderes públicos, seja pela apatia quase inerente aos indivíduos, diariamente acossados pelas necessidades e prazeres da vida cotidiana. Dentro dessa perspectiva, a participação política está intimamente relacionada ao modo como os indivíduos percebem o mundo público, ou seja, a política e os governantes, como coisas alheias ao leque de questões com as quais precisam de fato interagir e que, basicamente, dizem respeito ao mundo privado.

Neste artigo, problematizo alguns elementos desse debate e proponho como eixo principal de discussão não as TICs em si e suas múltiplas possibilidades incrementais, mas o próprio fluxo de informação disponibilizado pelas instituições governamentais visando o consumo de indivíduos e grupos.

\footnotetext{
1 Versões preliminares deste artigo foram apresentadas no Seminário Internacional Participação política, democracia e eleições: o ponto de vista dos brasileiros, UFG/2008 e no $6^{\circ}$ Encontro da ABCP, Campinas/2008. Agradeço às estudantes Elisa Signates, Laryssa Vieira, Uianã Cruvinel e Gabrielle Bertolli pelo trabalho voluntário dedicado ao projeto Atores políticos e informação não midiatizada: a presença da mídia alternativa na vida política democrática, desenvolvido no DCS/UFG.

2 Dentre outros, Norris (2002) utiliza a terminologia cyperpessimismo e cyberotimismo para analisar perspectiva dos analistas em relação às TICs.

${ }^{3}$ Os termos fazem alusão, respectivamente, a J.J. Rousseau e J. Schumpeter.
} 


\section{1 - Breve revisão da literatura}

Não é novidade afirmar que, de modo geral, a democracia não conseguiu resolver o problema da distância entre representantes e representados, entre os atores políticos institucionalizados e a sociedade civil. Este abismo mostra-se crescente e de solução duvidosa e os custos da informação permanecem na lista dos problemas insolúveis. Contudo, é importante interrogar se os indivíduos querem mesmo outras atribuições e preocupações para além da sua esfera cotidiana e se os políticos desejam, na prática, aproximações mais significativas.

De qualquer modo, a apatia e a distância entre representantes e representados permanecem na lista das ameaças constantes à perenidade da democracia, não obstante alguns países de democracia consolidada, como os Estados Unidos, apresentarem continuamente níveis consideráveis de indiferença dos indivíduos frente aos processos eleitorais. Por seu turno, a informação política segue entre os componentes elementares para o alargamento do interesse político ou, ao menos, para deixar as informações ao alcance de todos, indivíduos e sociedade civil organizada.

Aqui nos deparamos com um dos calcanhares de Aquiles desse debate, afinal, o mundo ocidental aprendeu a valorizar a mídia comercial como única fonte confiável de informação, ao mesmo tempo em que se consolidou uma percepção negativa quanto às informações oriundas do Estado, dos governantes em geral, enfim, da burocracia pública. É possível que esta laceração da confiança pública tenha vínculos no que Habermas descreveu como mudança estrutural da esfera pública (HABERMAS, 1984), quando a emergente burguesia teve que buscar mecanismos de contraposição ao poder aristocrático ora estabelecido.

No imaginário ocidental, a mídia comercial preenche de modo inequívoco o lugar de anteparo entre Estado e sociedade, tal qual postulado por liberais republicanos como Arendt (1989), para os quais a sociedade não pode prescindir de mecanismos de proteção contra possíveis investidas totalitárias do poder público e dos governantes.

O problema é que a mídia comercial não mais consegue preencher todos os requisitos desse guardião imaginário da democracia e da sociedade, pois evoluiu em direção às características de qualquer segmento do mercado econômico, com interesses e características próprios.

Economicamente vigoroso e altamente competitivo, o mercado da informação permanece errático em termos de pluralidade de fontes e de espaço para vozes dissonantes. Segundo Entman (1989), a competição garante o livre mercado, entretanto, compele produtores e emissores de informações noticiosas a constantes cortes nos custos e à submissão da oferta ao que está na moda, sejam idéias, temas, personagens e, inclusive, em relação à arena política. Mesmo com a 
BEZERRA, H. D. Atores políticos, informação e democracia.

internet, a mídia comercial ainda utiliza as mesmas e restritas agências de notícia enquanto produtoras primárias de conteúdos noticiosos. No quesito diversidade, também não se verifica um incremento significativo quanto à pluralidade de vozes e temas, o que representa certo empobrecimento do debate público, da esfera pública. Ou seja, a mídia comercial não consegue suprir as necessidades de informação dos indivíduos.

Ainda assim, devido a sua abrangência e poder econômico, é relevante ponderar que a mídia comercial permanece como principal lócus de emissão de informações cotidianas. Por outro lado, mostra-se incapaz de provocar positivamente a atenção e a participação dos indivíduos nos processos da vida política. Isto seria um problema de incapacidade de persuasão ou de conteúdo informacional? Para Entman (op.cit.), a mídia comercial realmente não pode ser tomada como o melhor guardião da democracia nem educador cívico, pois se trata de um mercado que, historicamente, tem se deixado pautar pelos interesses dos anunciantes públicos e privados, incluindo neste leque de interessados a própria classe política.

Entretanto, não apenas os profissionais do mercado midiático trabalham com informação, especialmente a informação política. O mercado político também dispõe de uma série de mecanismos de produção e circulação de informação. Sem desprezar a influência da mídia, Entman (op.cit.) apontou um déficit significativo na esfera dos atores do mercado político, os quais deveriam ser incluídos sempre que o assunto é a incumbência de formar/informar os cidadãos e ajudar a melhorar quantitativa e qualitativamente a participação. Para este autor, o incremento da informação política e da formação do cidadão enquanto sujeito participativo na vida pública depende severamente do fluxo de informações oriundo dos atores políticos, sejam os partidos, o poder executivo ou o legislativo.

Conteúdos informativos disponibilizados pelos atores políticos e ofertados gratuitamente à sociedade compõem uma alternativa ao fluxo de informação oriundo dos veículos de comunicação tradicionais, constituindo, assim, conjuntamente à mídia comercial, um amplo mercado de informação. Não obstante as críticas e desconfianças em relação às iniciativas governamentais no campo da comunicação, muitas vezes inteiramente válidas, é preciso considerar que espaços de informação protagonizados pelos atores políticos estabelecem mecanismos de interação direta entre a sociedade e as instituições políticas e governamentais. Decerto que toda informação alternativa deve ser ofertada com o objetivo de incrementar o fluxo comercial e nunca de substituí-lo, agregando novas possibilidades de comunicação e de interação. Seguramente, a mídia comercial ainda predomina enquanto emissor das informações que incrementam a esfera pública e a sociedade civil, o que inclusive garante certa responsividade por parte dos governantes. 
Para Entman (op.cit.), há uma lacuna que, necessariamente, deveria ser ocupada pelos atores da arena política de modo diferenciado dos esquemas de persuasão político-partidária.

\section{2 - Problematização temática}

Na pesquisa que deu origem a este artigo (Cf. nota 1), estamos analisando os sites dos Poderes Executivo e Legislativo do estado de Goiás e da Prefeitura de Goiânia. Investigamos ainda os sites e espaços de interação direta disponibilizados pelos partidos políticos. Contudo, por se tratar de uma área de estudos recente, especialmente no Brasil, considero relevante divulgar as considerações teóricometodológicas que vêm norteando a pesquisa empírica. O comportamento dos atores políticos é analisado tendo como referência alguns dos pontos apontados na literatura como relevantes para a qualidade da relação entre representantes e representados, bem como para a própria estabilidade da democracia (ARATO, 2002).

\section{1 - Convergência digital: barateamento dos custos e exclusão informacional}

Considerando o problema dos custos da informação e as dificuldades logísticas inerentes às mídias de massa tradicionais, como rádio e televisão, a internet começa a constituir um ambiente privilegiado, permitindo a difusão de informações com agilidade e custos acessíveis. A internet é considerada pelos cyberotimistas como uma grande janela de oportunidades para uma mudança quantitativa e qualitativa da participação política da sociedade, inclusive quanto à criação de fóruns decisórios típicos de uma democracia direta.

No entanto, em países de grandes desigualdades, é preciso antes de tudo avaliar em que medida a maioria da população está tendo acesso à rede mundial de computadores. O caso brasileiro ainda não é animador, pois, apesar do recente boom econômico, no campo do uso das novas tecnologias ainda é imperativo avançar muito. A $3^{a}$ Pesquisa TIC Domicílios e Usuários de $2007^{4}$ constatou que 76\% dos domicílios urbanos brasileiros não possuem computador e que a posição socioeconômica incide diretamente na capacidade de acesso a este bem (Tabela 1).

\footnotetext{
${ }^{4}$ CETIC - Centro de Estudos sobre as Tecnologias da Informação e da Comunicação - <www.cetic.br>; Comitê Gestor da Internet no Brasil - <www.cgi.br>.
} 
Tabela 1 - Proporção de domicílios com computador, Brasil, 2007

\begin{tabular}{|c|c|c|c|}
\hline \multicolumn{2}{|c|}{$\begin{array}{l}\text { \% sobre o total de } \\
\text { domicílios }\end{array}$} & Sim & Não \\
\hline \multicolumn{2}{|l|}{ Total } & 24 & 76 \\
\hline \multirow{5}{*}{$\begin{array}{l}\text { Regiões } \\
\text { do país }\end{array}$} & SUDESTE & 30 & 70 \\
\hline & NORDESTE & 11 & 89 \\
\hline & SUL & 31 & 69 \\
\hline & NORTE & 13 & 87 \\
\hline & CENTRO-OESTE & 26 & 74 \\
\hline \multirow{6}{*}{$\begin{array}{l}\text { Renda } \\
\text { Familiar }\end{array}$} & Até $\mathrm{R} \$ 380$ & 3 & 97 \\
\hline & $\mathrm{R} \$ 381 \cdot \mathrm{R} \$ 760$ & 9 & 91 \\
\hline & $\mathrm{R} \$ 761-\mathrm{R} \$ 1.140$ & 24 & 76 \\
\hline & $\mathrm{R} \$ 1.141 \cdot \mathrm{R} \$ 1.900$ & 40 & 60 \\
\hline & $\mathrm{R} \$ 1.901 \cdot \mathrm{R} \$ 3.800$ & 66 & 34 \\
\hline & $\mathrm{R} \$ 3.801$ ou mais & 72 & 28 \\
\hline \multirow{4}{*}{$\begin{array}{l}\text { Classe } \\
\text { Social }\end{array}$} & A & 88 & 12 \\
\hline & $B$ & 63 & 37 \\
\hline & $\mathrm{C}$ & 25 & 75 \\
\hline & $\overline{D E}$ & 4 & 96 \\
\hline
\end{tabular}

Fonte: CETIC, $3^{a}$. Pesquisa TIC Domicílios e Usuários de 2007.

O baixo acesso à tecnologia pode ser constatado também no modo como conseguem fazer uso da web, pois, considerando a tendência à convergência digital por parte dos atores governamentais, é expressivo constatar que $83 \%$ dos domicílios não têm acesso à internet, ou seja, a maioria dos brasileiros habita a categoria dos excluídos do fluxo informacional via web, total ou parcialmente (Tabela 2). O acesso no local de trabalho, em escolas e 'lan houses' oferece possibilidades limitadas, sendo que, no caso do mercado não gratuito, os usuários pagam por hora de acesso e para impressão de documentos. 


\section{Tabela 2 - Proporção de domicílios com acesso à internet, Brasil, 2007}

\begin{tabular}{|l|c|c|c|}
\hline \multicolumn{2}{|l|}{ \% sobre o total de domicílios } & Sim & Não \\
\hline Total & & 17 & 83 \\
\hline \multirow{4}{*}{$\begin{array}{l}\text { Regiões } \\
\text { do país }\end{array}$} & SUDESTE & 22 & 78 \\
\cline { 2 - 4 } & NORDESTE & 7 & 92 \\
\cline { 2 - 4 } & SUL & 21 & 78 \\
\cline { 2 - 4 } & NORTE & 5 & 95 \\
\hline \multirow{4}{*}{$\begin{array}{l}\text { Renda } \\
\text { Familiar }\end{array}$} & Até $\mathrm{R} \$ 380$ & 1 & 98 \\
\cline { 2 - 4 } & $\mathrm{R} \$ 381-\mathrm{R} \$ 760$ & 4 & 95 \\
\cline { 2 - 4 } & $\mathrm{R} \$ 761-\mathrm{R} \$ 1.140$ & 15 & 85 \\
\cline { 2 - 4 } & $\mathrm{R} \$ 1.141-\mathrm{R} \$ 1.900$ & 28 & 72 \\
\cline { 2 - 4 } & $\mathrm{R} \$ 1.901-\mathrm{R} \$ 3.800$ & 54 & 46 \\
\cline { 2 - 4 } & $\mathrm{R} \$ 3.801$ ou mais & 66 & 34 \\
\hline \multirow{4}{*}{$\begin{array}{l}\text { Classe } \\
\text { Social }\end{array}$} & $\mathrm{A}$ & 82 & 18 \\
\cline { 2 - 4 } & $\mathrm{B}$ & 50 & 50 \\
\cline { 2 - 4 } & $\mathrm{C}$ & 16 & 84 \\
\cline { 2 - 4 } & $\mathrm{DE}$ & 2 & 98 \\
\hline
\end{tabular}

Fonte: CETIC, $3^{\text {a }}$. Pesquisa TIC Domicílios e Usuários de 2007.

A pesquisa também revelou que, entre os domicílios com acesso à internet, $42 \%$ ainda utilizam acesso discado, o que significa um modo operacional de custo mais elevado e acessibilidade menos eficaz. Obviamente, é a parcela mais pobre da população que encontra maiores dificuldades no acesso à informação via web, pois, ainda que tenha acesso às novas tecnologias, as ferramentas das quais dispõe são ultrapassadas em comparação àquelas utilizadas pelos indivíduos de maior renda (Tabela 3). 
Tabela 3 - Tipo de conexão para acesso à internet no domicílio (\% sobre o total de domicílios com acesso à internet),

Brasil, 2007

\begin{tabular}{|c|c|c|c|c|c|c|c|c|}
\hline & & \multirow[t]{2}{*}{ Discada } & \multicolumn{5}{|c|}{ Banda Larga } & \multirow{2}{*}{$\begin{array}{l}\text { Outros/ } \\
\text { Não } \\
\text { sabe/ } \\
\text { Não } \\
\text { respon- } \\
\text { deu }\end{array}$} \\
\hline & & & $\begin{array}{l}\text { Total } \\
\text { Banda } \\
\text { larga } \\
\end{array}$ & ADSL & $\begin{array}{l}\text { Via } \\
\text { cabo }\end{array}$ & $\begin{array}{l}\text { Via } \\
\text { rádio }\end{array}$ & $\begin{array}{c}\text { Via } \\
\text { satélite }\end{array}$ & \\
\hline \multicolumn{2}{|l|}{ Total } & 42 & 50 & 25 & 16 & 8 & 1 & 8 \\
\hline \multirow{5}{*}{$\begin{array}{l}\text { Regiões } \\
\text { do } \\
\text { País }\end{array}$} & SUDESTE & 45 & 46 & 19 & 20 & 6 & 2 & 9 \\
\hline & NORDESTE & 47 & 46 & 17 & 13 & 15 & 1 & 6 \\
\hline & SUL & 34 & 58 & 43 & 6 & 8 & . & 8 \\
\hline & NORTE & 43 & 47 & 14 & 8 & 24 & 1 & 10 \\
\hline & $\begin{array}{l}\text { CENTRO- } \\
\text { OESTE }\end{array}$ & 24 & 68 & 42 & 15 & 11 & - & 8 \\
\hline \multirow{5}{*}{$\begin{array}{l}\text { Renda } \\
\text { Familiar }\end{array}$} & Até $\mathrm{R} \$ 760$ & 45 & 41 & 17 & 13 & 9 & 2 & 14 \\
\hline & $\begin{array}{l}\mathrm{R} \$ 761 \mathrm{a} \\
\mathrm{R} \$ 1.140\end{array}$ & 50 & 43 & 22 & 12 & 7 & 1 & 8 \\
\hline & $\begin{array}{c}\mathrm{R} \$ 1.141 \mathrm{a} \\
\mathrm{R} \$ 1.900\end{array}$ & 43 & 51 & 24 & 19 & 8 & - & 6 \\
\hline & $\begin{array}{c}\mathrm{R} \$ 1.901 \mathrm{a} \\
\mathrm{R} \$ 3.800\end{array}$ & 39 & 54 & 30 & 16 & 7 & 2 & 6 \\
\hline & $\begin{array}{l}\mathrm{R} \$ 3.801 \\
\text { ou mais }\end{array}$ & 27 & 64 & 29 & 24 & 10 & 1 & 9 \\
\hline \multirow{4}{*}{$\begin{array}{l}\text { Classe } \\
\text { Social }\end{array}$} & A & 17 & 78 & 43 & 26 & 8 & 1 & 5 \\
\hline & $B$ & 41 & 52 & 26 & 18 & 7 & 1 & 7 \\
\hline & $C$ & 48 & 43 & 22 & 12 & 8 & 1 & 9 \\
\hline & $\mathrm{DE}$ & 37 & 39 & 10 & 11 & 16 & 2 & 24 \\
\hline
\end{tabular}

Fonte: CETIC, 3a. Pesquisa TIC Domicílios e Usuários de 2007.

Quanto ao uso do governo eletrônico, a pesquisa apontou que em 2007 um total de $25 \%$ dos brasileiros maiores de 16 anos fez uso da internet para interagir com órgãos públicos, sendo que $59 \%$ destes usuários buscaram apenas informações sobre CPF. Entre aqueles que não usaram a internet para este tipo de interação, $49 \%$ disseram que não o fizeram em função da preferência por contato pessoal. 
OPINIÃO PÚBLICA, Campinas, vol. 14, n², Novembro, 2008, p.414-431

A pesquisa IBGE 2006, Perfil dos Municípios Brasileiros, divulgada em 2007, revela um crescimento significativo do uso da internet como ferramenta de disponibilização de informação. A grande maioria dos municípios participa do fluxo de informação, mas não oferece à sociedade mecanismos de interação. A pesquisa IBGE também classificou os sites segundo o estágio de desenvolvimento, tipificando em "informativos", "interativos" e "transacionais". Foram classificados como "transacional' os sites consideradas no topo do desenvolvimento, ou seja, que participam do fluxo informacional e possibilitam a troca de valores e serviços, por exemplo, matrícula na rede de ensino, pagamento de impostos e similares (Tabela 4).

As páginas transacionais, consideradas as mais desenvolvidas, têm como vocação básica a cobrança de taxas e impostos e a prestação de serviços. É certo que já constituem um avanço, mas estão longe de oferecer os tais mecanismos de interação ou de democracia direta.

Tabela 4 - Municípios, total e com página da prefeitura na internet, por situação, localização, classificação e serviços disponibilizados na página, segundo grandes regiões e classes de tamanho da população

\begin{tabular}{|c|c|c|c|c|c|c|}
\hline \multirow{4}{*}{ Grandes Regiões } & \multicolumn{6}{|c|}{ Municípios } \\
\hline & \multirow{3}{*}{ Total } & \multicolumn{5}{|c|}{ Com página da prefeitura na Internet (\%) } \\
\hline & & \multirow{2}{*}{$\begin{array}{l}\text { Total } \\
\text { (A) }\end{array}$} & \multirow{2}{*}{$\begin{array}{l}\text { Total } \\
\text { (R) }\end{array}$} & \multicolumn{3}{|c|}{ Classificação } \\
\hline & & & & Informativa & Interativa & Transacional \\
\hline Brasil & 5564 & 2674 & 48,1 & 68,8 & 24,4 & 6,8 \\
\hline Até 5000 hab. & 1371 & 508 & 37,0 & 83,5 & 13,9 & 2,6 \\
\hline De 5.001 a 10.000 hab. & 1290 & 475 & 36,8 & 80,9 & 15,5 & 3,6 \\
\hline $\begin{array}{l}\text { De } 10.001 \text { a } 20.000 \\
\text { hab. }\end{array}$ & 1292 & 590 & 45,7 & 73,4 & 23,3 & 3,3 \\
\hline $\begin{array}{l}\text { De } 20.001 \text { a } 50.000 \\
\text { hab. }\end{array}$ & 1033 & 604 & 58,5 & 65,1 & 30,0 & 4,9 \\
\hline $\begin{array}{l}\text { De } 50.001 \text { a } 100.000 \\
\text { hab. }\end{array}$ & 311 & 247 & 79,4 & 52,2 & 33,6 & 14,2 \\
\hline $\begin{array}{l}\text { De } 100.001 \text { a } 500.000 \\
\text { hab. }\end{array}$ & 231 & 214 & 92,6 & 32,2 & 43,9 & 23,9 \\
\hline Mais de 500.000 hab. & 36 & 36 & 100,0 & 16,7 & 36,1 & 47,2 \\
\hline Norte & 449 & 115 & 25,6 & 74,0 & 20,0 & 6,0 \\
\hline Nordeste & 1793 & 626 & 34,9 & 71,2 & 24,4 & 4,4 \\
\hline Sudeste & 1668 & 930 & 55,8 & 65,8 & 27,1 & 7,1 \\
\hline Sul & 1188 & 778 & 65,5 & 70,0 & 22,6 & 7,4 \\
\hline Centro-Oeste & 466 & 225 & 48,3 & 67,6 & 22,2 & 10,2 \\
\hline
\end{tabular}

Fonte: IBGE, Pesquisa de Informações Básicas Municipais MUNIC 2006. 
BEZERRA, H. D. Atores políticos, informação e democracia.

Assim, se há de fato um interesse crescente pela convergência digital, o que fazer com os indivíduos que não dispõem de acesso às novas tecnologias? Ignorar a exclusão desses indivíduos ou investir paralelamente em mídias tradicionais? A diminuição dos tradicionais ambientes de interação direta, como sedes partidárias, gabinetes, governos móveis e outros, pode prejudicar ainda mais aqueles que se encontram excluídos do mundo tecnológico? Ainda poderíamos explorar a questão dos baixos níveis educacionais da população, pois a navegação na web com vistas à exploração de sites governamentais e interação com mecanismos decisórios supõe um nível adequado de preparo formal.

\section{2 - Cidadania: assistência social ou inclusão política?}

O debate entre "cyberotimistas" e "cyberpessimistas" revela uma preocupação considerável com o fato de os indivíduos mostrarem-se mais ou menos participativos, mais ou menos interessados nos problemas do mundo público. $\mathrm{Na}$ perspectiva dos "cyberotimistas rousseanianos", os cidadãos são potencialmente interessados no processo político e as novas TICs constituem elementos capazes de incrementar e facilitar sua participação nas decisões do mundo público.

$\mathrm{Na}$ contramão, os "cyberpessimistas schumpeterianos" não visualizam grandes possibilidades das TICs no que se refere à participação ativa dos indivíduos, haja visto que as atividades do mundo público são pouco atrativas em todos os aspectos, além de demandarem tempo e conhecimento, elementos de alto custo agregado. Para esses, os que participam são sempre os mesmos e, de qualquer modo, os indivíduos acabam delegando as decisões a algum representante, seja no trabalho, no bairro ou mesmo na família, o modelo preferido é o da representação por delegação.

As duas perspectivas contêm elementos interessantes, mas, para o caso brasileiro, de pouca comprovação empírica quando cotejados com o modo como os cidadãos são percebidos pelos poderes públicos. Assim, diante do impasse teóricometodológico, partiu-se dos dados coletados na pesquisa empírica para uma modelagem conceitual dessa cidadania conforme percebida e praticada pelos atores políticos governamentais.

O primeiro modelo é caracterizado pela perspectiva de um cidadão. consumidor, para o qual se oferta uma série de informações inerentes à organização e controle dos deveres dos cidadãos para com o poder público. Neste caso, cidadão que interessa ou que é percebido é o pagador de impostos e tarifas, que, basicamente, se relaciona com a burocracia da máquina pública. 
O segundo modelo denota a percepção de um cidadão-desamparado, carente, dependente das ofertas realizadas pelo poder público e, assim, alvo certo de políticas de assistência social. As clivagens básicas quanto a cor/raça, sexo, idade e renda predominam no modo de se organizar a oferta, já que os demandantes ou potenciais demandantes não têm voz. A cidadania é percebida de acordo com a oferta de políticas e, para ser cidadão, é preciso, principalmente, depender de alguma dessas ofertas.

Em resumo, em nenhum desses modelos, o "cidadão" é convidado ou estimulado à participação política. É o poder público que provê os bens, direitos e serviços necessários a seu bem estar. O fluxo de informação protagonizado pelos governantes e pela burocracia é limitado às políticas prontas e ofertadas, com público-alvo já recortado, sendo que, em muitos casos, os programas já são realizados.

Não há espaço para a participação cidadã nos moldes da democracia deliberativa ou participativa direta, posto que o cidadão percebido pelo poder público representa simplesmente o consumo de bens e serviços sem abertura para qualquer atuação nas decisões que antecedem a oferta dessas políticas.

O fluxo de informação é quase sempre de mão única, dos representantes para os representados, do Estado para a sociedade, exceto nos períodos eleitorais.

\section{3 - Informação e controles democráticos horizontais e verticais}

Devido a sua natureza e características, a mídia comercial ainda é considerada por muitos como uma espécie de última fortaleza em defesa das instituições democráticas. Supondo que isto seja verdade, e que possa, de fato, exercer algum controle do poder, coibir abusos e dar vazão à transparência político. administrativa, ainda assim o seu fluxo discursivo também depende em boa medida das informações oriundas das instituições integrantes da esfera política/estatal. Sendo assim, é relevante considerar que, devido aos interesses entre mercado político e mercado da informação, os demais segmentos socioeconômicos e os indivíduos não devem prescindir de mecanismos de controle autônomos em relação à informação midiatizada. No âmbito da sociedade civil, a tarefa de controlar o poder, coibir abusos e avaliar a transparência político-administrativa dos governantes pode ser uma atribuição facultada a quem o desejar fazê-lo, indivíduos e grupos, desde que o fluxo de informações seja plural e irrestrito. 
A perspectiva de Arato (2002) sobre os imbricamentos entre esfera pública e sociedade civil é bastante útil para a compreensão não apenas dessas arenas enquanto lugares de operacionalização das vontades individuais e coletivas, mas, também, quanto às possibilidades de realização do controle civil sobre as atividades governamentais.

"Na minha concepção esfera pública e a sociedade civil existem conjuntamente: o primeiro conceito aponta para os processos parcialmente institucionalizados de comunicação que são tão importantes na política democrática, ao passo que o segundo conceito trata do substrato organizacional dos grupos, associações e movimentos que são necessários tanto para a generalização da experiência de comunicação como para sua influência política. Enquanto o público atua no importante papel de monitorar as ações que serão posteriormente recompensadas ou sancionadas, as associações civis preparam os eleitores para participação coletiva e para reagir de modo que façam diferença nos destinos eleitorais de seus representantes. Atualmente, todos sabem que os que detêm cargos eletivos devem, acima de tudo, temer o julgamento retrospectivo dos grupos organizados" (ARATO, 2002, p. 98).

Neste sentido, possibilitaria um sistema de controle e avaliação diferenciado do sistema de punição e recompensa comandado pela mídia comercial, o qual se realiza, na prática, em função de interesses particularistas dos políticos e controladores da informação. Isto, certamente, não contribui para aproximar representantes e representados e, segundo Patterson (1993), ajuda a consolidar um viés anti-político entre os indivíduos que desconfiam da política enquanto mecanismo ótimo para distribuição de bens e recursos.

Quando informar não faz parte da agenda de prioridades das instituições governamentais, os controles democráticos passam a condição de controles burocráticos, o que favorece os jogos ocultos da política e trajetória de políticos envolvidos em corrupção, tráfico de influência e esquemas similares. Além disso, se a sociedade não está preparada para processar o conjunto de informações disponibilizadas (SANCHEZ, 2003), o poder da burocracia e dos representantes do povo permanece intocável. 


\section{4 - Accountability política vs, propaganda}

Accountability política tem sido indicada como uma das principais ferramentas de democratização da atividade política, especialmente governamental. Acredita-se que a disponibilização de dados, especialmente se for conduzida pelas instituições, pode incrementar a esfera pública e, conseqüentemente, a capacidade de avaliação retrospectiva por parte de indivíduos e grupos. No entanto, algumas questões surgem como pedras no caminho deste debate.

A primeira questão é a redução de accountability à transparência no trato com o dinheiro público, um tema delicado, dada sua relevância para o combate à corrupção e para a própria democratização das relações políticas. Será que apenas realizando uma boa prestação de contas o governante está realizando plenamente o que se espera da accountability política? Certamente não, o que nos conduz ao segundo problema: como realizar accountability política sem enveredar pela propaganda direcionada para a persuasão político-eleitoral de interesse do grupo que está no poder?

Acontece que informação e propaganda acabam por preencher as duas faces de uma mesma moeda, qual seja o direito do cidadão-representado conhecer o que está sendo feito por seus representantes. Por exemplo, tanto para o poder legislativo quanto para o poder executivo, o ponto máximo de accountability política seria a possibilidade de correlacionar, na íntegra, as respectivas plataformas de campanha com as realizações e comportamento dos representantes eleitos. Novamente, a tarefa de prestação de contas esbarra em empecilhos ético-legais visà-vis a legislação sobre propaganda eleitoral e governamental.

Este debate transcende a própria questão da difusão de informação e resvala, conforme exemplo anterior, inclusive em questões conceituais sobre o que se compreende por comunicação pública. Na prática, distinguir accountability política de propaganda política não é uma tarefa simples, até porque, para as instituições governamentais, o caminho da propaganda tem se mostrado mais interessante e, portanto, com maior uso por parte dos atores políticos, inclusive os governamentais.

A comunicação governamental sucumbiu ao poder dos releases direcionados à mídia comercial ou à produção estanque de informações objetivando garantir antecipadamente a aprovação popular nos pleitos posteriores. No caso do Brasil, com eleições a cada dois anos, comprometimento e interferência direta dos caciques políticos nos processos de escolha dos candidatos, o que vale é a máxima "ricuperiana", ou seja, "o que é bom a gente mostra e o que é ruim a gente esconde". 
BEZERRA, H. D. Atores políticos, informação e democracia.

Concluindo, realizar accountability política sem incluir os aspectos negativos das políticas públicas e demais ações governamentais é transformá-la em propaganda com fins exclusivos de divulgação de informação positiva para o realizador, uma prática comum no Brasil e que objetiva simplesmente edulcorar com apelos sedutores o interesse dos governantes. Esta prática contribui para reforçar a tese de que a mídia comercial é a única fonte confiável de informação, pois o Estado/governantes quando informam o fazem de modo circunscrito a parcialidades do interesse do emissor.

\section{5 - Responsividade e políticas públicas}

Outra dimensão que tem sido indicada como relevante para a democracia e para a expansão qualitativa da cidadania é a responsividade, ou seja, a criação de mecanismos que possibilitem maior aproximação entre as preferências dos cidadãos e o processo de formulação de políticas públicas. Sendo assim, nada mais importante do que o conjunto de informações disponibilizadas cotidianamente pelas instituições governamentais acompanhado de mecanismos de interação, o que pode ser um indicativo da ressonância da esfera pública e/ou da sociedade civil organizada junto aos poderes constituídos.

O suposto, contudo, é que, na democracia representativa, os cidadãos esperam contar com o trabalho dos representantes legitimamente eleitos para buscar soluções adequadas aos problemas que surgirem durante seus mandatos. Isto não basta? Os adeptos da democracia deliberativa ou da ampliação da participação dos cidadãos nos processos decisórios acreditam que os limites do modelo representativo engessam a criatividade e as preferências dos indivíduos (SANTOS, 2002).

A experiência do conhecido Orçamento Participativo/OP, realizado pelas gestões do Partido dos Trabalhadores durante mais de uma década no município de Porto Alegre, Rio Grande do Sul - modelo disseminado para outros municípios, não apenas sob gestões petistas -, demonstra que não há consenso quanto à legitimidade do OP enquanto mecanismo de coleta e gestão das preferências dos cidadãos. Dentre as alegações, tem destaque o problema da diminuição do poder dos representantes legitimamente eleitos para legislar e buscar soluções para as demandas populares. Em resumo, para muitos, a participação da sociedade fica bem resolvida quando circunscrita aos processos eleitorais e eventuais consultas temáticas por meio de referendos e plebiscitos. 
Mas, se, de fato, responsividade é um indicador de democracia, é relevante que os órgãos públicos criem mecanismos para o cidadão expressar suas preferências. A grande questão é se haverá, realmente, representantes interessados em formular políticas de acordo com preferências manifestadas via mecanismos abertos de consulta popular.

Não basta uma enquete simplória como as que atualmente são oferecidas em alguns sites governamentais, afinal, mecanismos de interação direta ou de participação decisória devem mesclar informação sobre os processos e consulta acerca de diretrizes e metas. A tramitação do processo deve incluir as deliberações finais, o processo de implantação e mecanismos de avaliação. Assim, teríamos o processo de produção de políticas públicas na íntegra, com responsividade.

Em uma versão amparada nas novas TCls, o Orçamento Participativo virtual realizado pela gestão do Prefeito Fernando Pimentel, no município de Belo Horizonte em Minas Gerais, surge como caso a ser estudado com fins de verificar se, de fato, cumpriu a missão de estimular a participação política direta dos indivíduos. É preciso verificar também se as preferências resultantes da consulta via web foram colocadas em prática, ou seja, transformadas em políticas. Todavia, independente do resultado dessa participação cidadã, é um exemplo de que a internet pode oferecer mecanismos facilitadores de interação política e inclusão dos cidadãos nos processos decisórios.

\section{Considerações finais}

Boa parte dos materiais bibliográficos, dados empíricos e de pesquisa utilizados para a realização deste artigo foram acessados e copiados via web, o que justifica o entusiasmo dos cyberotimistas, que consideram a internet a nova revolução no que tange à disseminação de informação e a conseqüente expansão da participação dos cidadãos nos processos decisórios relativos ao mundo público.

Ocorre que ainda há muitos pontos obscuros nessa questão, para além mesmo da disposição dos indivíduos para uma vida mais participativa, mais devota à busca de soluções para os muitos problemas da polis, ou seja, a história ainda não é suficientemente favorável nem aos "cyberotimistas rousseanianos" nem aos "cyberpessimistas schumpeterianos".

Neste artigo, procurei discorrer sobre alguns dos problemas pertinentes a esse debate. A convergência digital e a dificuldade de acesso às novas TCls, como é o caso do Brasil, implicam em exclusão de uma grande parcela da população de toda informação disseminada via web, bem como dos potenciais mecanismos de interação direta. 
Questionou-se também o modelo de cidadão percebido e praticado nos sites governamentais, sendo que, de modo geral, não há qualquer referência à participação dos indivíduos nos processos decisórios, seja expressando preferências, seja deliberando sobre quaisquer questões do mundo público. A questão dos controles democráticos horizontais e verticais foi também avaliada, concluindo-se que a mídia comercial ainda predomina enquanto principal lócus de disseminação de informação, bem como enquanto guardião da democracia e dos interesses da sociedade.

O tema da accountability política foi examinado vis-à-vis uma discussão sobre propaganda e comunicação governamental, pois, conforme exposto, informação política ainda é considerada preferencialmente enquanto tema inerente à divulgação de resultados positivos, dos feitos dos governantes e demais gestores públicos. Outro problema inerente à accountability é a desconfiança da sociedade em relação à informação ofertada pelo Estado/governos.

Por fim, tratou-se do assunto responsividade, considerado pelos especialistas como um dos elementos fundamentais, juntamente com accountability, da chamada governança cidadã. Um governo responsivo deveria oferecer mecanismos de consulta para as demandas da sociedade e a conseqüente elaboração de políticas públicas aportadas nessa vontade revelada. O dilema da democracia representativa tem sido a superação do mito da representação como o lugar de revelação dessa vontade, pois é o representante o portador da vontade particular, transformada em vontade geral à medida que a representação é exercida na vida política cotidiana.

Concluindo, as novíssimas tecnologias de informação e comunicação, de fato, abrem possibilidades diversas para a participação dos atores políticos no fluxo de informação, complementando o que já é ofertado pela mídia comercial. Ainda, podem ser usadas como ferramentas para potencializar a criação de mecanismos de interação entre Estado / sociedade, governos / cidadãos, representantes / representados. Não há como antecipar se essas ferramentas irão, na prática, impulsionar a participação dos indivíduos no cotidiano das decisões políticas. É preciso, antes de tudo, interesse por parte dos cidadãos e dos governantes. 


\section{Referências bibliográficas}

ARATO, A. "Representação, soberania popular, e accountability". Lua Nova, São Paulo, n55. $56,2002$.

ARENDT, H. As origens do totalitarismo. São Paulo: Companhia das Letras, 1989.

BEZERRA, H.D. Mídia e Política. Goiânia: Editora da UCG, 2007.

BEZERRA, H.D. e BERTOLLI, G.; CRUVINEL, U.; SIGNATES, E.; VIEIRA, L. Atores políticos, informação e accountability: Goiás, um estudo de caso. In: PAIVA, D. e BEZERRA, H.D. (orgs.). Panorama da política em Goiás. Goiânia: Editora da UCG, no prelo.

BORGES, A. "Governança e política educacional: a agenda recente do Banco Mundial". Revista Brasileira de Ciências Sociais. São Paulo, vol.18, n52, 2003.

BRAGA, S.S. "O impacto da internet no funcionamento das instituições democráticas brasileiras: um estudo sobre a informatização dos legislativos estaduais no Brasil". Cidade do México: Anais do $2^{\circ}$ Congresso da Associação Latino-americana de Ciência Política, 2004. Disponível em: <http://www.colmex.mx/personal/ces/sgt/ponencias.htm>. Acesso em: 20 jul. 2005.

"Internet e Política: a informatização dos órgãos legislativos na América do Sul". Campinas: Anais do $3^{\circ}$ Congresso da Associação Latino-americana de Ciência Política, 2006.

CETIC, 3a. Pesquisa TIC Domicílios e Usuários de 2007. Disponível em: <www.cetic.br>. Acesso em: 10 mar. 2008.

ENTMAN, R. Democracy without citizens: media and the decay of American politics. New York: Oxford University Press, 1989.

GUIDELINES FOR THE CONTENT AND STRUCTURE OF PARLIAMENTARY WEB SITES. Disponível em: <http://www.ipu.org/cntr-e/web.pdf>. Acesso em: 11 nov. 2007.

HABERMAS, J. Mudança estrutural da esfera pública. Rio de Janeiro: Tempo Brasileiro, 1984[1961]. 
Brasileiro, 1977.

Direito e Democracia: entre facticidade e validade. Rio de Janeiro: Tempo

IBGE. Pesquisa de Informações Básicas Municipais MUNIC 2006. Disponível em <www.ibge.gov.br>. Acesso em: 2 abr. 2008.

MARQUES, F. P. J. A. "Debates políticos na internet: a perspectiva da conversação civil". Opinião Pública, Campinas, vol.12, n¹, 2006.

NORRIS, P. Digital Divide? Civic Engagement, Information Poverty \& the Internet Worldwide. Cambridge: Cambridge University Press, 2002. Disponível em: <www.pipanorris.com>. Acesso em: 12 abr. 2008.

PATTERSON, T. E. Out of order. New York: Knopf, 1993.

SANCHEZ, O. A. "O poder burocrático e o controle da informação". Lua Nova, n58, 2003.

SANTOS, B. de S. Democratizar a democracia: os caminhos da democracia participativa. Rio de Janeiro: Civilização Brasileira, 2002.

SCHUMPETER, J. Capitalismo, socialismo, democracia. Rio de Janeiro: Editora Fundo de Cultura, 1961 [1949].

SILVA, S. P. "Graus de participação democrática no uso da Internet pelos governos das capitais brasileiras". Opinião Pública, Campinas, vol.11, n², 2005.

Heloisa Dias Bezerra - heloisadb@fchf.ufg.br

Recebido e aprovado para publicação em agosto de 2008. 